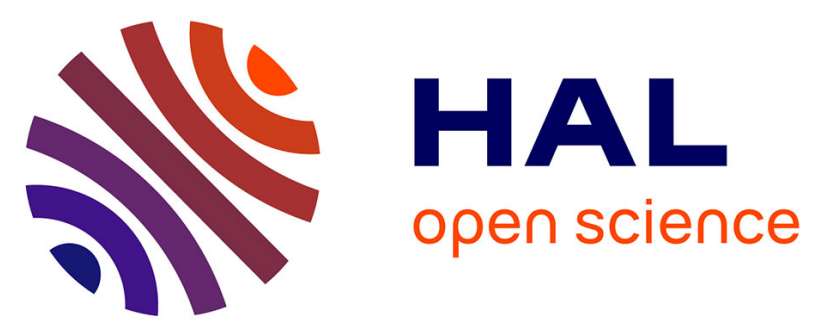

\title{
The effects of education in psychiatry on attitudes towards antidepressants in nursing students: A cross-sectional study
}

J.-V. Blanc, S. Mouchabac, P. Nuss, L. Malandain, N. Lapidus, F. Ferreri

\section{- To cite this version:}

J.-V. Blanc, S. Mouchabac, P. Nuss, L. Malandain, N. Lapidus, et al.. The effects of education in psychiatry on attitudes towards antidepressants in nursing students: A cross-sectional study. Nurse Education in Practice, 2020, 45, pp.102781. 10.1016/j.nepr.2020.102781 . hal-02986157

\section{HAL Id: hal-02986157 \\ https: / hal.sorbonne-universite.fr/hal-02986157}

Submitted on 4 Nov 2020

HAL is a multi-disciplinary open access archive for the deposit and dissemination of scientific research documents, whether they are published or not. The documents may come from teaching and research institutions in France or abroad, or from public or private research centers.
L'archive ouverte pluridisciplinaire HAL, est destinée au dépôt et à la diffusion de documents scientifiques de niveau recherche, publiés ou non, émanant des établissements d'enseignement et de recherche français ou étrangers, des laboratoires publics ou privés. 
The effects of education in psychiatry on attitudes towards antidepressants in nursing students: a cross-sectional study

J.-V.Blanc, S.Mouchabac, P.Nuss, L.Malandain, N.Lapidus, F.Ferreri

\section{Abstract}

Background: Stigma associated with depression and antidepressants is strong among the general population but also among patients and health professionals.

Objectives: This cross-sectional study is aimed at: 1) evaluating the knowledge and attitude towards antidepressant by nursing student; 2) exploring the association between instruction in psychiatry and representation of depression and antidepressants.

Participants: 2037 undergraduate students from 10 French nursing schools were invited to participate in 2017, 1475 (73\%) completed the questionnaire.

Methods: The self-report questionnaire included the Drug Attitude Inventory (DAI) and questions about representation on depression and antidepressant. Four groups of students were built: 1) pre-teaching group (PT) as a reference group, 2) clinical training in psychiatry $(\mathrm{CT}), 3$ ) receiving mental health theoretical education $(\mathrm{TE}), 4)$ receiving both $(\mathrm{CT}+\mathrm{TE})$.

Results: The mean (standard deviation) DAl score was negative: $-1.9( \pm 4.4)$ with only $40 \%$ of the nursing students conveying a positive attitude towards antidepressant. A combination of CT and TE was associated with a more positive attitude towards antidepressant in comparison with the PT condition. The CT+TE group was more prone to view antidepressants as effective and safe.

Conclusion: There is strong stigma against depression/antidepressants among nursing student. Education combined with clinical experiences in psychiatry improved these representations.

Keywords: antidepressant, stigma, depression, nurse, student, psychiatry, belief 


\section{Contribution of the Paper}

What is already known about the topic?

- Stigma linked to depression and antidepressants is strong among the general population but also within health professionals

- Unfavorable attitudes to treatment among nurses are associated with poorer quality of care

What does this paper adds?

- Only $40 \%$ of the nursing students express a positive attitude towards antidepressant

- An association of theoretical education and clinical training improve these attitudes 


\section{Introduction}

Major depression is a chronic and recurrent disorder, affecting 350 million people worldwide (Whiteford et al., 2013). It is the third leading cause of global disability in 2015 (Vos et al., 2016), depressive disorders are expected to become first by 2030 according to the World Health Organization. In contrast, only $44 \%$ of individuals that meet the criteria for Major Depressive Episode (MDE) benefit from an appropriated care (Marcus et al., 2012). Despite guidelines and available effective treatments (in particular antidepressants), the recommended duration of treatment (4 to 9 months after clinical remission) is rarely observed. In France, according to the National Health Insurance, the duration of antidepressant treatment is shorter than one month in more than $60 \%$ of the treated individuals (Tournier et al., 2011).

Converging studies point out that negative representations, beliefs and concerns about antidepressants are associated with poor treatment adherence (Acosta et al., 2013; Burnett-Zeigler et al., 2014; Lu et al., 2016). Stigma associated with mental health is thus a strong factor in the low rate of appropriate care of depression (Thornicroft, 2008). Dudley defined stigma as stereotypes or negative views attributed to a person or groups of people when their characteristics or behaviors are viewed as different from or inferior to societal norms (Dudley, 2000). In this context, depressive manifestations in individuals are often ascribed to personal weakness and strongly seen as a direct consequence of environmental stress; both interpretations associated with decreased likelihood of proper care. A nationwide survey examined the French general population's conceptions about depression in 2005 (Chan Chee et al., 2009). A subgroup of the sample declared being in agreement with a psychological (25.3\%) or biological (31.8\%) explanation of depression. Conversely, another $13.4 \%$ emphasized on the global negative outcome of depression while $7.3 \%$ viewed depression as a response to some psychosocial stress; $6.1 \%$ clearly stigmatized the disease, while $6.1 \%$ rejected the validity of depression as a medical category. Younger age, low academic achievement and low income were found in groups with the worst opinion on depression. Lack of information on depression or refutation of depression as a valid category predominates in this subgroup (Chan Chee et al., 2009).

Among careers, nurses are key to depression identification, acceptation and medication administration. They are usually the closest interlocutors of patients, 
supporting them on a daily basis, listening to their preoccupations about their disorder and medication. Nurses are thus significant facilitators for disease acceptation and medication adherence (Roh et al., 2009; Spoelstra et al., 2015; Wu and Pai, 2014). As individuals, nurses are influenced by the prevailing negative representations towards individuals with mental illness prevailing in the general population (Nordt et al., 2006). Interestingly, Caldwell et al. showed that mental health nurses are more convinced than the general population of the utility of interventions to treat depression, including antidepressants, (Caldwell and Jorm, 2000). A positive attitude of health professionals towards health issues is crucial to improve access, adherence, and quality of care of patients with mental illnesses. An evidence-based and accurate information about the severity of depression and benefit/risk ratio of antidepressant treatment is thus likely to be indirectly beneficial to depressed patients (Wu et al., 2011). Treatment optimization encompasses issues such as identification of the need for help, but also information on depression via psychoeducation, in particular regarding the duration of treatment and undesirable therapeutic effects (Wu et al., 2011). In this context, the negative opinion held by healthcare professionals on depression may lead to decreased quality of care in depression (Suwalska et al., 2016) on line with other stigmatized conditions such as obesity (Phelan et al., 2015) and HIV infection (Wagner et al., 2014), by affecting the objectivity of the given information.

More specifically, few studies evaluated the knowledge and representation of the treatment of depression in undergraduate health professionals. Istilli et al. found that $52 \%$ of participants expressed doubts about antidepressant effectiveness, even after they have received instruction on this topic (Istilli et al., 2010).

The influence of training on stigma among mental health professionals still remains unclear. For instance, opportunity to interact with mental health patients during induction training is arguably expected to improve the representation of the disease. This is supported by the "contact hypothesis", described by Allport in the early 1950s, suggesting that specific social contact under certain conditions creates a positive intergroup coalescence, which will improve intergroup relations (Ewalds-Kvist et al 2012, Forbes H. 2008). This beneficial effect has been questioned. Several studies could find no change in mental illness prejudice of medical and nursing students after a clinical practicum in psychiatry service (Callagan et al., 1997, Chang et al., 2017, 
Choi et al., 2016). To our knowledge, no study addressed the role of psychiatry teaching on attitude towards depression and antidepressant among nursing students (Blanc et al., 2017a).

The present study was conducted in a nursing student population: its aim was to evaluate knowledge and attitude towards depression and antidepressant, and explore the influence of clinical training and instruction on the representation on both topics. Our assumption was that a better knowledge regarding depression and antidepressants in nursing students is likely to change their attitude and, consequently, decrease stigma on depression, ultimately leading to an indirect benefit for patients.

\section{Methodology}

\subsection{Setting}

This cross-sectional study took place in April 2017 in 10 nursing schools in the Paris area. Subjects were asked to complete the Drug Attitude Inventory (DAI) and a complementary questionnaire. Online data was collected and anonymized. The research was approved by the Nurse Monitoring Educational Committee and ethical approval from the institutional review board (IRB) at the Sorbonne University; in addition, approval was obtained from the school department of nursing in the eleven universities before data collection. Students were informed that they were free to not answer and gave written consent. Questionnaires were anonymous.

\subsection{Participants and design}

The investigated population was composed of nursing students in their either first, second or third year of training.

Subgroup analyses were conducted among 4 groups: 1) pre-teaching group (PT) who had received neither training nor education, 2) had a only clinical training (CT) in psychiatry, 3) received only a theoretical education (TE) about mental health and depression, and 4$)$ received both $(C T+T E)$. Clinical training in psychiatry took place in various settings, both psychiatric hospitals and community mental health centers. 
The training lasted 5 to 10 weeks. The daily contact with patients suffering from various mental disorders was supervised by a senior nurse; theoretical education consisted of 40 hours of courses by teaching psychiatrists. The educational program included a nurse's role in mental health as well as specific information on mental disorders (including depression and its treatment). Education did not specifically address issues such as stigma about depression or beliefs about antidepressants.

To build these four groups, students were asked to give information about the psychiatric education they received: clinical training (CT) and/or theoretical education (TE). This educational status allowed us to determine the four categories of students. According to the large number of students solicited, we were expecting to obtain homogeneous groups.

\subsection{Evaluation tools}

The Drug Attitude Inventory (DAl) was the main assessment tool of the study. It is a commonly used evaluation instrument to measure the attitudes of patients but also the general population (De las Cuevas and Sanz, 2007) towards psychotropic drugs (Hogan et al., 1983) including antidepressants (Blanc et al., 2017b, Brook et al, 2003). Validated in French, concise and easy to administer, DIA-10 has wellestablished psychometric properties with good test-retest reliability (0.92) and homogeneity (0.71) (Droulout et al., 2003, Nielsen et al., 2012). This self-report scale has ten items rated as True or False. A True response for six of the items (1, 3, 4, 7, $9,10)$ and a False response for the other four items $(2,5,6,8)$ reflect a positive attitude towards the medication (fig. 1 ). They are scored +1 . Otherwise, the response is scored -1 . The final score is the sum of the ten items.

Sets of complementary questions were also designed to explore student specific knowledge and opinions about depression and antidepressants (see table 2) and were purposelessly discussed by a focus group. Authors built this group to respond to the problem studied. To not hinder the quality of discussions, we avoided the presence of any hierarchical links between the members. The focus group was made up of 3 psychiatrists (lead authors of the study), 3 nurse directors of Nursing Training Institutes and 3 nursing students from different schools of these directors. Questions were sources derived from literature as followed: 
- Questions based on selected items of the Beliefs about Medicine Questionnaire (Samalin et al., 2017).This eighteen-item questionnaire has strong and replicated psychometric properties. It rates on Lickert scales and explores four aspects of perceptions and beliefs about medical treatments: beliefs about their harmfulness, perception of doctors' overconfidence in these treatments, links with expected side effects and the need to adhere to the prescription.

- A list of common beliefs found in general population about depression and treatment (Angermeyer et al., 2013). Using a "vignette method" originally developed in Germany, Angermeyer and al. measured on a five points Lickert scales the causal attributions of twelve possible causes of depression in four domains (psychosocial stress, childhood adversity, biogenetics causes and intra-psychic causes) in general population. They assessed opinions about different treatment methods: three evidence-based psychiatric treatments (psychotropic medication, psychotherapy, relaxations techniques) and three 'alternative' treatments (natural remedies, mediation, acupuncture).

- Level of basic knowledge about antidepressants (Roh et al., 2009). In this study, Roh et al. didn't use psychometrics instruments, but select questions to evaluate dispositions towards using psychiatric services or receiving psychiatric drugs. Participants were able to choose responses from supplied answers.

- Probability to recommend the prescription of an antidepressant for oneself or a relative (Roh et al., 2009) ;

\subsection{Data analysis}

The study examined the rate of positive attitude toward antidepressants (defined by Hogan et al. as DAI score $\geq 0$ ), as a function of the level of instruction received or clinical experience acquired (Hogan et al., 1983). After removing missing data, the three subgroups (CT, TE, and $C T+T E$ ) were compared to the reference (PT) condition and between themselves in terms of: frequencies and percentages of positive attitude toward antidepressants. In addition, answers on the complementary questions were compared between groups. 
Reference characteristics were compared among groups with chi-square tests. Positive attitude toward antidepressants and responses to DAl items for groups CT, TE and CT+TE were compared to the reference group with univariable logistic regression, using DAl items as the response variable and students group as the explanatory covariate. Odds ratios (OR) are given with their $95 \%$ confidence interval (Cl).

Assuming two unbalanced groups of 400 and 200 students, the sample size permitted to detect for instance a 3.2 OR for a $10 \%$ proportion in the first group or a 1.1 OR for a $30 \%$ proportion, with an $80 \%$ power and a $5 \%$ type I error.

A p-value below 0.05 was considered significant for all tests. All analyses were conducted using statistical software R 3.4 (R Core Team, 2017).

\section{Results}

Among the 2037 students invited to participate in the study, 1475 (73\%) fully completed the questionnaire. No statistical difference was found between the 4 groups regarding baseline characteristics. Most students were female (85.3\%; $n=1225)$ and $76.8 \%(n=1301)$ were in the 18 to 25 age group (table 1$)$.

\subsection{Relation between DAl scores and psychiatric education}

The mean (+/-SD) DAl score of the overall student population was negative -1.9 (4.4). An overall positive attitude towards antidepressants was found only in $40 \%$ of the population (table 2). A more positive attitude towards antidepressants was found in the group that received the combination of clinical training and theoretical education (CT+TE) $(45 \%, \mathrm{OR}=1.67$ [95\% Cl: 1.31, 2.15], $\mathrm{p}<0.0001)$ and TE only $(40 \%, \mathrm{OR}=1.35(1.00,1.83) \mathrm{p}<0.05)$ compared with the PT group $(32 \%)($ Table 2$)$. DAI improvement was also observed in TE and CT groups versus PT, but did not reach statistical significance.

\subsection{Beliefs and knowledge modified by psychiatric education}

An improvement in knowledge about onset of action of antidepressants, beliefs about effectiveness of antidepressant and rate of recommendation of treatment for a relative was observed in the TE, CT and CT+TE groups compared with the PT condition. Belief that a patient with depression is a not a "real" patient as well as 
"antidepressants do more harm than good" was lower only for the CT+TE group compared to the PT condition (with $6 \%$ and $33 \%$ for CT+TE vs. $10 \%$ and $46 \%$ in PT, respectively, $p<0.001$ for both). Regarding the assumptions: "consider taking antidepressants for oneself or others in case of prescription", "that antidepressant do not treat the cause of depression", and "that doctors prescribe too much antidepressants" an increased opinion was observed only in the CP + TE group (48\%, $70 \%$ and $72 \%$ vs. $41 \%, 64 \%$ and $66 \%$ in PT, respectively; $p=0.03,0.02$ and $0.01)$.

\subsection{Beliefs and knowledge not modified by psychiatric instruction}

Belief that psychotherapies are more effective than antidepressant were not modified by any $C T, T E$, or $C T+T E$ compared with the $P T$ condition (respectively, $p=0.74$; $p=0.52$ and $p=0.09$ ). Belief that a patient with depression is different from a patient with another illness were not modified either by any CT, TE, or CT + TE compared with the PT condition (respectively, $p=0.72 ; p=0.75$ and $p=0.15$ ). This opinion is quite frequent, shared by $44 \%$ of the overall student population.

\section{Discussion}

The main result of our study is the identification of a strong mistrust towards antidepressants and the presence of stigma concerning depression in a large proportion of nursing students.

This negative attitude, evaluated with the global DAI score, is comparable to the result of studies made on similar samples (score of -1.9 in 229 French nursing students (Blanc et al., 2017a). De las Cuevas et al. found less negative attitude towards antidepressant in patients compared to the general population (mean DAI of -0.7 vs. +3.6) (De las Cuevas and Sanz, 2007). In our study the attitudes towards antidepressants are worse compared to both groups.

The literature shows mixed results on the influence of theoretical and clinical education on knowledge, attitudes to antidepressants and representation of depression (Arrue et al., 2018; Blanc et al., 2017a ; Chang et al., 2017, Choi et al., 2016 , Simon and Verdoux, 2017). Choi et al. showed no significant change in mental health prejudice before and after clinical training in 63 nursing students (Choi et al., 
2016), and Chang et al found more negative attitudes after a clinical placement (Chang et al., 2017). In line with the present study, association of general psychiatric education and clinical training in the psychiatry ward was associated with a reduction of stigmatizing attitudes about mental health disorders in a medical student population (Simon and Verdoux, 2017).

Nevertheless, most studies indicate that appropriate knowledge about depression and antidepressants correlate with more positive attitude towards antidepressants (Roh et al., 2009). A bidirectional effect is observed between stigma to depression and negative attitude towards antidepressants (Allara et al., 2015; Gronholm et al., 2017).

Among the various information conveyed during teaching, retention varies according to the taught topics in the studied population. Issues such as onset of action and effectiveness of antidepressants were seemingly easy to be correctly addressed in the TE and CT + TE subgroups. Yet, as much as half of the questioned students mentioned that patients with depression differ from those with another medical condition. Furthermore, despite specific psychiatric teaching, a majority of nursing students still considers antidepressants as harmful and with addictive potential. Of concern too, is the fact that there is no observed change in opinion about alleged excess in antidepressant prescriptions by psychiatrists. We cannot but confront this result with studies showing that $75 \%$ of patient suffering from major depressive disorder do not receive adequate treatment (Grolleau et al., 2008; Hämäläinen et al., 2009).

Adequate mental health in future nurses is crucial as a nurse's career unavoidably confronts highly emotional situations as well as institutional pressure. Increasing the knowledge about depression and antidepressants could benefit the mental health of nursing students. As mentioned by Roh et al. in a population of medical students, psychiatric education about depression increasing the student's ability to seek treatment for themselves in the case of psychological distress (Roh et al., 2009).

In France, Nursing Training Institutes have partnerships with Universities. Nurse training is available for postgraduate students. It takes place over 3 years. Candidates must be at least 17 years old to be admitted to training. The nursing diploma certifies that the student has obtained 180 European Credit Transfer System 
(ECTS): 120 ECTS for teaching units and 60 ECTS for clinical nursing practice. Among the different clinical trainings, a 10-week clinical practice in psychiatry (internship) is compulsory.

Advanced Practice Nurses (APN) (i.e. Psychiatric \& Mental Health Clinical Nurse Specialist or Psychiatric \& Mental Health Nurse Practitioner, in the US) could certainly have a sub-specialization in management of mood disorders. In France, regarding the drug treatment, the APN should be able to perform the renewal of the drug prescription or dosage adjustment for mood stabilizers or antidepressants. Recently promoted by the Ministry of Health, a specific teaching module on antidepressants and the stigma surrounding depression will be included in the training course of APN in psychiatry.

The overall negative opinion about major depression, patients with depression, and antidepressants in future health professionals are likely to play a role in poorer patient outcomes. A conjunction of prejudice and negative attitude towards mental problems in general (Schafer et al., 2011) along with suspicion of antidepressant efficacy and tolerance in health professionals is likely to reduce proper access to care and optimal outcome in people suffering from depression.

\subsection{Study limitations}

The cross sectional design does not allow for the examination of the direct effect of education on a prospective manner on the same group of individuals over time. A randomized procedure allocating specific educational programs would have also been ideal. Nevertheless, the socio-demographic characteristics of the 4 groups are identical over the teaching years as well as variables affecting DAI, indicative of a good comparability between groups. A post-graduation study after some years of nurse practice using the same questionnaire will also be of interest. It will look at the remanence effect of the positive attitude changes observed during the training years as well as later changes in the more reluctant students. The use of another tool, as the Beliefs about Medicine Questionnaire (BMQ), could also be useful to complete the DAI (Samalin et al., 2017), but was not available in French at the time the study was designed. The BMQ explore general beliefs about medication, as well as concerns and necessity. Thus, it could be interesting to administer both tools. As 
$73 \%$ of the students accepted to participate to the study, it shows an interest for mental health issue.

\subsection{Recommendations and pedagogical proposals (fig. 2)}

The present study emphasizes the critical and beneficial role of clinical practice combined with teaching in psychiatry to improve attitude towards antidepressants and reduce the stigma of depression. This advocates for an appropriate and intentional educational program during the induction-training period about mental health issues, reinforced by well-supervised psychiatric clinical training.

Erroneous preconception about depression and antidepressants were found in a quite high proportion of nurse students. Psychiatric education was shown to be able to improve knowledge and decrease stigma. We assume that specific teaching in psychiatry, emphasizing on major depression frequency, causes, manifestations, treatment, somatic impact, and handicap is likely to decrease stigma and misconceptions, as shown by education given to college students (Yamaguchi et al., 2013). In particular, information about the underlying biological causes of mental disorders - with its subsequent rational for a medication use - was shown to lead to better acceptance for both in the general population (Schomerus et al., 2012). Communication about the benefit/risk ratio of antidepressants is also likely to be useful in this context (Wu et al., 2011).

Obviously, a greater impact for de-stigmatization will be obtained via association of theoretical and in-site education combined with proactive and small group learning. International recommendations such as CANMAT (Canadian Network for Mood and Anxiety Treatments) also advocates for an optimistic attitude during teaching towards treatment of individuals with mental health problems (Murrihy et al., 2009; Piette et al., 2015).

While social contact with mental health patients is an effective way to reduce stigma (Yamaguchi et al., 2013), that was not the case in our study: clinical practice alone failed to reduce stigma. We can hypothesize that during their practice in psychiatric wards, nursing students focused mostly in the more acute, severe and relapsing patients. To benefit from the "contact hypothesis", it may be effective to include interaction with patients in a recovery process during their nurse training. 
Specific research on mental health issues in the nursing community will also be able to raise awareness on that topic, not only among nurses but also the general population. Seen as "trustful, ethical and honest" (Pinto-Foltz and Logsdon, 2009), nurses are in a unique position to positively impact mental health issues in the general population. In France, nursing students, as well as most healthcare professionals during, their training years, are about to be in charge of a public health prevention program called "sanitary service" (Vaillant et al, 2018). Thus, an important prerequisite before initiating this program is to investigate stigma towards mental health problems in nursing students and ways to decrease it is. 


\section{Conclusion}

In nursing students, level of stigma against depression and negative attitude towards antidepressants are strong and higher compared to the general population. Knowledge on mental health issues combined with clinical experiences in general psychiatric wards have been shown to be the key to improving these representations. Both high levels of induction training in psychiatry - because of the complexity of mental illness - and individualized support for students are needed to achieve professional excellence among nursing students.

This research is independent with no subsidy of any sort, either specific grant from public, commercial Funding Agencies, or non-profit Association.

\section{References}

Acosta, F., Rodríguez, L., Cabrera, B., 2013. Creencias sobre la depresión y sus tratamientos: variables asociadas e influencia de las creencias en la adherencia. Rev. Psiquiatr. Salud Ment. 6, 86-92. https://doi.org/10.1016/j.rpsm.2012.08.001

Allara, E., Ferri, M., Bo, A., Gasparrini, A., Faggiano, F., 2015. Are mass-media campaigns effective in preventing drug use? A Cochrane systematic review and meta-analysis. BMJ Open 5, e007449. https://doi.org/10.1136/bmjopen-2014-007449

Angermeyer, M.C., Millier, A., Rémuzat, C., Refaï, T., Toumi, M., 2013. Attitudes and beliefs of the French public about schizophrenia and major depression: results from a vignette-based population survey. BMC Psychiatry 13. https://doi.org/10.1186/1471244X-13-313

Arrue M, Zarandona J, Hoyos Cillero I. Nursing students' alternative beliefs regarding care for patients suffering from depression. Nurse Educ Pract. 2018 Mar;29:185-190. doi: 10.1016/j.nepr.2018.01.006.

Blanc, J.-V., Lapidus, N., Nuss, P., Mouchabac, S., Ferreri, F., 2017a. The concerning attitudes and beliefs of nursing students toward antidepressants and depression. L’Encéphale. https://doi.org/10.1016/j.encep.2017.10.003

Blanc, J.-V., Curt, F., Bruno, N., 2017b. Adherence, attitudes and concerns regarding antidepressants in a sample of inpatients with a major depression episode: Who is to blame? L'Encéphale 43, 192-194. https://doi.org/10.1016/j.encep.2015.11.007

Brook O, van Hout H, Nieuwenhuyse H, Heerdink E. Impact of coaching by community pharmacists on drug attitude of depressive primary care patients and acceptability to patients; a randomized controlled trial. Eur Neuropsychopharmacol. 2003 Jan;13(1):1-9. 
Burnett-Zeigler, I., Kim, H.M., Chiang, C., Kavanagh, J., Zivin, K., Rockefeller, K., Sirey, J.A., Kales, H.C., 2014. The association between race and gender, treatment attitudes, and antidepressant treatment adherence: Attitudes and antidepressant adherence. Int. J. Geriatr. Psychiatry 29, 169-177. https://doi.org/10.1002/gps.3984

Caldwell, T.M., Jorm, A.F., 2000. Mental Health Nurses' Beliefs About Interventions for Schizophrenia and Depression: A Comparison with Psychiatrists and the Public. Aust. N. Z. J. Psychiatry 34, 602-611. https://doi.org/10.1080/j.14401614.2000.00750.x

Callaghan, P., Shan, C. S., Yu, L. S., Ching, L. W. and Kwan, T. L. (1997), Attitudes towards mental illness: testing the contact hypothesis among Chinese student nurses in Hong Kong. Journal of Advanced Nursing, 26: 33-40. doi:10.1046/j.13652648.1997.1997026033.x

Chan Chee, C., Beck, F., Sapinho, D., Guilbert, P., 2009. La dépression en France. INPES, coll. Études santé, Saint- Denis.

Chang S, Ong HL, Seow E, et al. Stigma towards mental illness among medical and nursing students in Singapore: a crosssectional study. BMJ Open 2017;7:e018099. doi:10.1136/bmjopen-2017-018099

Choi, H., Hwang, B., Kim, S., Ko, H., Kim, S., Kim, C., 2016. Clinical Education In psychiatric mental health nursing: Overcoming current challenges. Nurse Educ. Today 39, 109-115. https://doi.org/10.1016/j.nedt.2016.01.021

De las Cuevas, C., Sanz, E.J., 2007. Attitudes toward psychiatric drug treatment: the experience of being treated. Eur. J. Clin. Pharmacol. 63, 1063-1067. https://doi.org/10.1007/s00228-007-0358-5

Droulout, T., Liraud, F., Verdoux, H., 2003. [Relationships between insight and medication adherence in subjects with psychosis]. L'Encephale 29, 430-437.

Dudley JR. Confronting stigma within the services system. Social Work. 2000;45:449-455.

Ewalds-Kvist B, Högberg T, Lützén $\mathrm{K}$, et al. Student nurses and the general population in Sweden: trends in attitudes towards mental illness. Nord J Psychiatry 2013;67:164-70.doi:10.3109/08039488.2012.694145

Forbes H "Contact Hypothesis." International Encyclopedia of the Social Sciences. . Retrieved March 18, 2018 from Encyclopedia.com: http://www.encyclopedia.com/social-sciences/applied-and-social-sciencesmagazines/contact-hypothesis

Grolleau, A., Cougnard, A., Bégaud, B., Verdoux, H., 2008. Congruence between diagnosis of recurrent major depressive disorder and psychotropic treatment in the 
general population. Acta Psychiatr. Scand. 117, 20-27.https://doi.org/10.1111/j.16000447.2007.01109.x

Gronholm, P.C., Henderson, C., Deb, T., Thornicroft, G., 2017. Interventions to reduce discrimination and stigma: the state of the art. Soc. Psychiatry Psychiatr. Epidemiol. 52, 249-258. https://doi.org/10.1007/s00127-017-1341-9

Hämäläinen, J., Isometsä, E., Sihvo, S., Kiviruusu, O., Pirkola, S., Lönnqvist, J., 2009. Treatment of major depressive disorder in the Finnish general population. Depress. Anxiety 26, 1049-1059. https://doi.org/10.1002/da.20524

Hogan, T.P., Awad, A.G., Eastwood, R., 1983. A self-report scale predictive of drug compliance in schizophrenics: reliability and discriminative validity. Psychol. Med. 13, 177-183.

Istilli, P.T., Miasso, A.I., Padovan, C.M., Crippa, J.A., Tirapelli, C.R., 2010. Antidepressants: knowledge and use among nursing students. Rev. Lat. Am. Enfermagem 18, 421-428.

Lu, Y., Arthur, D., Hu, L., Cheng, G., An, F., Li, Z., 2016. Beliefs about antidepressant medication and associated adherence among older Chinese patients with major depression: A cross-sectional survey: antidepressant and medication adherence. Int. J. Ment. Health Nurs. 25, 71-79.https://doi.org/10.1111/inm.12181

Marcus, M., Yasamy, M.T., van Ommeren, M., Chishom, D., Saxena, S., 2012. Depression-A global public health concern 2012. WHO Department of Mental Health and Substance Abuse.

Murrihy, R.C., Byrne, M.K., Gonsalvez, C.J., 2009. Testing an empirically derived mental health training model featuring small groups, distributed practice and patient discussion. Med. Educ. 43, 140-145. https://doi.org/10.1111/j.1365-

2923.2008.03256.x

Nielsen, R.E., Lindström, E., Nielsen, J., Levander, S., 2012. DAI-10 is as good as DAI-30 in schizophrenia. Eur. Neuropsychopharmacol. 22, 747-750.

https://doi.org/10.1016/j.euroneuro.2012.02.008

Nordt, C., Rössler, W., Lauber, C., 2006. Attitudes of Mental Health Professionals Toward People With Schizophrenia and Major Depression. Schizophr. Bull. 32, 709714. https://doi.org/10.1093/schbul/sbj065

Phelan, S.M., Burgess, D.J., Yeazel, M.W., Hellerstedt, W.L., Griffin, J.M., van Ryn, M., 2015. Impact of weight bias and stigma on quality of care and outcomes for patients with obesity. Obes. Rev. 16, 319-326. https://doi.org/10.1111/obr.12266

Piette, A., Muchirahondo, F., Mangezi, W., Iversen, A., Cowan, F., Dube, M., Peterkin, H.G.-, Araya, R., Abas, M., 2015. 'Simulation-based learning in psychiatry 
for undergraduates at the University of Zimbabwe medical school.' BMC Med. Educ. 15, 23. https://doi.org/10.1186/s12909-015-0291-8

Pinto-Foltz, M.D., Logsdon, M.C., 2009. Reducing Stigma Related to Mental Disorders: Initiatives, Interventions, and Recommendations for Nursing. Arch. Psychiatr. Nurs. 23, 32-40. https://doi.org/10.1016/j.apnu.2008.02.010

R Core Team, 2017. R: A language and environment for statistical computing.

Roh, M.-S., Jeon, H.J., Kim, H., Cho, H.J., Han, S.K., Hahm, B.-J., 2009. Factors influencing treatment for depression among medical students: a nationwide sample in South Korea. Med. Educ. 43, 133-139. https://doi.org/10.1111/j.13652923.2008.03255.x

Samalin, L., de Chazeron, I., Belzeaux, R., Llorca, P.-M., 2017. Exploratory analysis of the French version of the beliefs about medicines questionnaire in patients with severe mental disorders: Factorial structure and reliability in specific populations of schizophrenic, bipolar and depressive patients. PLOS ONE 12, e0173267. https://doi.org/10.1371/journal.pone.0173267

Schafer, T., Wood, S., Williams, R., 2011. A survey into student nurses' attitudes towards mental illness: Implications for nurse training. Nurse Educ. Today 31, 328332. https://doi.org/10.1016/j.nedt.2010.06.010

Schomerus, G., Schwahn, C., Holzinger, A., Corrigan, P.W., Grabe, H.J., Carta, M.G., Angermeyer, M.C., 2012. Evolution of public attitudes about mental illness: a systematic review and meta-analysis: Evolution of public attitudes. Acta Psychiatr. Scand. 125, 440-452. https://doi.org/10.1111/j.1600-0447.2012.01826.x

Simon, N., Verdoux, H., 2017. Impact of education program and clinical posting in psychiatry on medical students' stigmatizing attitudes towards psychiatry and psychiatric disorders. L'Encéphale. https://doi.org/10.1016/j.encep.2017.05.003

Spoelstra, S.L., Schueller, M., Hilton, M., Ridenour, K., 2015. Interventions combining motivational interviewing and cognitive behaviour to promote medication adherence: a literature review. J. Clin. Nurs. 24, 1163-1173. https://doi.org/10.1111/jocn.12738

Suwalska, J., Suwalska, A., Neumann-Podczaska, A., Łojko, D., 2016. Medical students and stigma of depression. Part I. Stigmatization of patients. Psychiatr. Pol. 51, 495-502. https://doi.org/10.12740/PP/OnlineFirst/63515

Thornicroft, G., 2008. Stigma and discrimination limit access to mental health care. Epidemiol. Psychiatr. Sci. 17, 14-19. https://doi.org/10.1017/S1121189X00002621

Tournier, M., Cougnard, A., Boutouaba-Combe, S., Verdoux, H., 2011. Duration of antidepressant drug treatment and its determinants in France. L'Encéphale, Therapeutique 37, S36-S41. https://doi.org/10.1016/j.encep.2010.06.007 
Vaillant L., Mise en œuvre du service sanitaire pour les étudiants en santé Retrieved March 18, 2018 from http://solidarites-

sante.gouv.fr/lMG/pdf/rapport_service_sanitaire_pr_vaillant.pdf

Vos, T., Allen, C., Arora, M., Barber, R.M., Bhutta, Z.A., Brown, A., Carter, A., 2016. Global, regional, and national incidence, prevalence, and years lived with disability for 310 diseases and injuries, 1990-2015: a systematic analysis for the Global Burden of Disease Study 2015. The Lancet 388, 1545-1602.

https://doi.org/10.1016/S0140-6736(16)31678-6

Wagner, A.C., Hart, T.A., McShane, K.E., Margolese, S., Girard, T.A., 2014. Health Care Provider Attitudes and Beliefs About People Living with HIV: Initial Validation of the Health Care Provider HIV/AIDS Stigma Scale (HPASS). AIDS Behav. 18, 23972408. https://doi.org/10.1007/s10461-014-0834-8

Whiteford, H.A., Degenhardt, L., Rehm, J., Baxter, A.J., Ferrari, A.J., Erskine, H.E., Charlson, F.J., Norman, R.E., Flaxman, A.D., Johns, N., Burstein, R., Murray, C.J., Vos, T., 2013. Global burden of disease attributable to mental and substance use disorders: findings from the Global Burden of Disease Study 2010. The Lancet 382, 1575-1586. https://doi.org/10.1016/S0140-6736(13)61611-6

Wu, R., Kemp, D.E., Sajatovic, M., Zhao, J., Calabrese, J.R., Gao, K., 2011.

Communication of potential benefits and harm to patients and payers in psychiatry: a review and commentary. Clin. Ther. 33, B62-76.

https://doi.org/10.1016/j.clinthera.2011.11.013

Wu, Y.P., Pai, A.L.H., 2014. Health Care Provider-Delivered Adherence Promotion Interventions: A Meta-Analysis. Pediatrics 133, e1698e1707.https://doi.org/10.1542/peds.2013-3639

Yamaguchi, S., Wu, S.-I., Biswas, M., Yate, M., Aoki, Y., Barley, E.A., Thornicroft, G., 2013. Effects of Short-Term Interventions to Reduce Mental Health-Related Stigma in University or College Students: A Systematic Review. J. Nerv. Ment. Dis. 201, 490-503. https://doi.org/10.1097/NMD.0b013e31829480df 